\title{
Dynamics of Regenerative Processes in Patients with Trophic Ulcers against the Background of Chronic Venous Hemodynamic Disturbances Using Therapy with Polydesoxyrinobonucleotides
}

\author{
Yelena Yu. Shapovalova, PhD, ScD*; Yuriy G. Baranovskiy, PhD; Tatyana A. Boyko, $\mathrm{PhD}$; \\ Fedor N. Ilchenko, PhD, ScD; Nicolay P. Barsukov, PhD, ScD; Pavel V. Vaschenko, PGS \\ Medical Academy named after S.I. Georgievsky of Vernadsky CFU, Simferopol, Russia
}

\begin{abstract}
The aim of this study was to analyze the healing of trophic ulcers (TUs) of the skin against the background of chronic venous insufficiency (CVI) after applying PDRN-therapy in a complex of therapeutic measures.

Materials and Methods: The study included 19 patients with TUs of various sizes and shapes (from 4 to $12 \mathrm{~cm}^{2}$ ) in the lower extremities with average duration from 4 weeks to 12 months, against the background of CVI. Patients were divided into two groups. Group 1 included 9 patients who received complex treatment along with using desoxyribonucleotide polymers (PDRNtherapy) according to the proposed methodology. Group 2 included 10 patients treated according to standard treatment of TUs. The area of wound defects was determined using the LesionMeter program. Skin thermometry was carried out using a B.Well WF-5000 medical infrared non-contact thermometer.

Results: We found that in patients of Group 1, who received PDRN-therapy in addition to standard treatment, by Day 20 there was a reduction in the TU area to $51.06 \pm 0.1 \%$ of the initial size; in patients of Group 2, who received only standard treatment, the TU area was $85.56 \pm 0.1 \%$ of the initial size. The temperature in the center of the ulcer and in its periphery increased in patients of Group 1 compared to patients of Group 2 by $2.79 \%$ and $2.74 \%$, respectively, indicating a better blood supply to the skin defect, possibly due to more active angiogenesis

Conclusion: The use of PDRN-therapy in the complex treatment of trophic ulcers on the background of CVI is clinically effective. The applied method contributed to accelerating the repair processes of the skin defect and improving vascularization, which reduced the healing time of trophic ulcers. (International Journal of Biomedicine. 2019;9(2):139-143.)
\end{abstract}

Key Words: trophic ulcer $\bullet$ polydesoxyribonucleotides $\bullet$ planimetry $\bullet$ thermometry

\section{Abbreviations}

CVI, chronic venous insufficiency; PDRN, polydesoxyribonucleotide; TU, trophic ulcer.

\section{Introduction}

Treatment of nonhealing defects of the skin, which are called ulcers, is one of the most ancient surgical problems, which has not lost its relevance up to the present day. An ulcer is a defect in tissues with a small tendency to heal, which

*Corresponding author: Prof. Yelena Yu. Shapovalova, PhD, ScD. Head of the Department of Histology \& Embryology of the Medical Academy named after S.I. Georgievsky of Vernadsky CFU. Simferopol, Russia.E-mail: Shapovalova_L@mail.ru arises against the background of impaired tissue reactivity due to external or internal causes that are, in intensity, beyond the limits of the body's adaptive capabilities..$^{(1)}$ The formation of trophic ulcers (TUs) is a consequence of chronic venous insufficiency (CVI), accompanied by a violation of hemodynamics at the microcirculatory level and aggravated by the influence of external factors. ${ }^{(2)} \mathrm{CVI}$ affects $25-30 \%$ of women and $10-20 \%$ of men In $40 \%-90 \%$ of patients, venous insufficiency is complicated by TUs. ${ }^{(3)}$ TUs are characterized by a low tendency to heal, frequent relapses, complexity and high cost of treatment. ${ }^{(4)}$ Chronic TUs that exist for more 
than 3 months do not heal spontaneously. ${ }^{(5)}$ They affect $2 \%$ of the US population and require treatment costing more than $\$ 3$ billion annually. ${ }^{(6)}$ At the same time, the problem of treating TUs of venous etiology is not currently resolved: The treatment is ineffective in $70 \%$ of patients. In this group, periods of temporary disability are high, resulting in $12.5 \%$ permanent disability. ${ }^{(7)}$ According to statistics, in industrialized countries, TUs lead to disability more often than tuberculosis, rheumatism and traffic injuries, taken together. ${ }^{(8)}$

Despite the development of various dressings and methods of treatment using a wide range of drugs, TUs against the background of CVI remain a significant problem. ${ }^{(3,8,9)}$ All this necessitates the search for new methods of treating this pathology.

Polydesoxyribonucleotides (PDRNs) are extracted from the semen of trout (Oncorhynchus mykiss) and salmon (Oncorhynchus keta). They are a combination of purine and phosphodiester bonds that make up the pyrimidine nucleotide monomer. ${ }^{(10)}$ Although PDRNs can be extracted from human and cattle placenta, PDRN preparations from salmon sperm are preferable in terms of possible contamination. A recent study evaluating the wound-healing effect of $O$. keta-derived PDRN for injection (Rejuvenex) and PDRN cream(Rejuvenex Cream), compared to the effects of $O$. mykiss-derived PDRN injection(Placentex), showed a slightly higher efficiency of $O$. keta-derived PDRN for injection (Rejuvenex). ${ }^{(11)}$ The use of polynucleotides is the newest specialized local therapy for the treatment of TUs. PDRNs are "prodrugs" that enrich cells with the right amount of mitogenic desoxyribonucleotides, desoxyribonucleosides, and also nitrogenous bases. PDRN, a DNA fragment of 50-2,000 bases, does not cause transformation at the genetic level and is completely harmless to the human body. PDRNs have the ability to replace the "broken" nitrogen bases of DNA with significant PDRN effectiveness. As a result, PDRN-based preparations remove incapable cell fragments, promote their recovery and activate the growth of young functional intracellular structures. ${ }^{(12)}$

Information about the positive effect of PDRNs on the healing of skin TUs of various etiologies is found in the scientific literature, but it is rare. ${ }^{(11,12)}$

The aim of this study was to analyze the healing of TUs of the skin against the background of CVI after applying PDRN-therapy in a complex of therapeutic measures.

\section{Materials and Methods}

The study included 19 patients with TUs of various sizes and shapes (from 4 to $12 \mathrm{~cm}^{2}$ ) in the lower extremities with average duration from 4 weeks to 12 months (Table 1), against the background of CVI.

The study was conducted in accordance with ethical principles of the WMA Declaration of Helsinki (1964, ed. 2013) and approved by the Ethics Committee of Medical Academy n.a. S.I. Georgievsky of Vernadsky CFU. Written informed consent was obtained from all participants.

Patients were divided into two groups. Group 1 included 9 patients who received complex treatment along with using PDRN according to the proposed methodology. Group 2 included 10 patients treated according to standard treatment of TUs. The groups were comparable in age, sex, severity of general condition, and nature of concomitant pathology.

Table 1.

Clinical characteristics of the patients according to the ClinicalEtiology-Anatomy-Pathophysiology (CEAP) classification

\begin{tabular}{|c|c|c|c|c|}
\hline \multirow{2}{*}{$\begin{array}{c}\text { CEAP } \\
\text { Clinical class }\end{array}$} & \multicolumn{2}{|c|}{$\begin{array}{c}\text { Gender } \\
(\mathrm{n} / \%)\end{array}$} & $\begin{array}{c}\text { Average } \\
\text { duration of } \\
\text { the skin defect, } \\
\text { months }\end{array}$ & $\begin{array}{c}\text { Average age, } \\
\text { years }\end{array}$ \\
\cline { 2 - 5 } & $\mathrm{M}$ & $\mathrm{F}$ & $8.9 \pm 0.2$ & $56.3 \pm 2.5$ \\
\hline $\mathrm{C} 5$ & $4 / 21.1$ & $5 / 26.3$ & $9.2 \pm 0.3$ & $56.4 \pm 1.6$ \\
\hline C6 & $5 / 26.3$ & $5 / 26.3$ & 9.3 \\
\hline
\end{tabular}

At the pre-hospital stage, all patients of the studied groups consulted with an angiosurgeon, received outpatient treatment at their place of residence, and in the case of a long wound history - in a general surgical hospital.

\section{Standard treatment}

All patients with TUs and CVI were subjected to compression with elastic knitwear; phlebotonics and systemic phleboprotectors were prescribed in accordance with the existing recommendations.

All patients of both groups were treated locally for TUs in a standard way, which included surgical treatment of a purulent focus, a removal of dead tissues, existing scab and fibrin layers, which often covered granulation tissue. Later, various antiseptics, including a $0.05 \%$ chlorhexidine digluconate solution, a $3 \%$ hydrogen peroxide solution, and a $1 \%$ dioxidine solution were topically used to clean the wound surface; we irrigated the wound surface during surgery or daily dressings. Then a gauze aseptic dressing was applied with a $0.1 \%$ betadine solution or ointment on a water-soluble basis (levocin, levomekol). All patients were prescribed antibiotic therapy from the first day of hospitalization in accordance with generally accepted regimens.

\section{PDRN-therapy}

Patients of Group 1 received PDRN extracted from the salmon semen with the commercial name "Plenhyage Medium" (I.R.A. Istituto Ricerche Applicate Sri; Italy) containing desoxyribonucleotide polymers with 50-2,000 pairs of nitrogenous bases. ${ }^{(13)}$ PDRN solution $(1.6 \mathrm{ml})$ was in a syringe with a needle in factory packaging. The drug was administered via subcutaneous and intracutaneous injections one time in 6 days along the periphery of the wound with a supplied $30 \mathrm{G} 0.3 \times 13 \mathrm{~mm}$ needle (about 20 injections of 0.05 $\mathrm{ml}$ each). ${ }^{(14)}$ The injections were made at a distance of $1 \mathrm{~cm}$ from the edge of the TU every $5 \mathrm{~mm}$ around the perimeter, distributing evenly the dose of the drug at the rate of $1 \mathrm{ml}$ per $10 \mathrm{~cm}^{2}$ of skin defect.

\section{Determination of TU area}

To study and objectivize the healing process of TUs in patients of both groups, the area of wound defects was determined using the LesionMeter program for the Android operating 
system, which is installed on a smartphone. To measure the surface area of the ulcer, a limb segment with a wound defect was photographed using this program, with a standard plastic bank card placed in view as a scaling standard. After that, in the photo the perimeter of the wound defect was encircled by the cursor and its area was automatically received in $\mathrm{cm}^{2}$. The result was recorded in the program archive. It should also be noted that this program is able to build line diagrams based on the accumulated data over time, which allows calculating the rate of epithelialization of a TU with high accuracy.

The area of the initial wound defect was determined upon admission of the patient to the hospital before the start of treatment and during the treatment period to determine the dynamics of wound healing on Days 4, 8, 12, 16 and 20, as well as at the end of the treatment period.

\section{Thermometry of TU}

Skin thermometry was performed to assess the effect of PDRN-therapy on the status of a TU. Skin thermometry was carried out using a B.Well WF-5000 medical infrared non-contact thermometer (UK, registration certificate for a medical product No. RZN 2013/1078 dated June 8, 2017) at 6 points of a TU: 3 points in the center of the ulcer and 3 points along its perimeter. Then the arithmetic mean temperature was determined according to the measurement localization.

Statistical analysis was performed using the statistical software «Statistica». (v6.0, StatSoft, USA) and Microsoft Excel 2007. Baseline characteristics were summarized as frequencies and percentages for categorical variables and as mean \pm SEM for continuous variables. The Mann-Whitney (U Test) was used to compare the differences between the two independent groups. The Wilcoxon criterion was used to compare the differences between the paired samples. A probability value of $P<0.05$ was considered statistically significant.

\section{Results}

Before starting treatment in all patients of Groups 1 and 2, the mean values of the area of the wound defect were comparable and did not show a statistically significant difference (Table 2). By Day 4 of treatment, the area of a TU on the background of CVI slightly decreased in both groups, but a statistically significant difference between the groups was still not detected.

\section{Table 2.}

Healing dynamics of TUs in the patients of study groups

\begin{tabular}{|c|c|c|c|}
\hline $\begin{array}{c}\text { Day of } \\
\text { observation }\end{array}$ & $\begin{array}{c}\text { Group 1 } \\
\left(\text { area of TU in } \mathrm{cm}^{2}\right)\end{array}$ & $\begin{array}{c}\text { Group 2 } \\
\left(\text { area of TU in } \mathrm{cm}^{2}\right)\end{array}$ & $P$-value \\
\hline 1 & $9.4 \pm 0.3$ & $9.7 \pm 0.3$ & $>0.05$ \\
\hline 4 & $9.1 \pm 0.2$ & $9.4 \pm 0.4$ & $>0.05$ \\
\hline 8 & $8.5 \pm 0.7$ & $9.2 \pm 0.2$ & $<0.05$ \\
\hline 12 & $7.3 \pm 0.4$ & $8.8 \pm 0.4$ & $<0.05$ \\
\hline 16 & $6.5 \pm 0.7$ & $8.6 \pm 0.2$ & $<0.05$ \\
\hline 20 & $4.8 \pm 0.4^{*}$ & $8.3 \pm 0.4$ & $<0.05$ \\
\hline
\end{tabular}

*- $P<0.05$ between Day 20 and Day 1 in Group 1
After 8 days of complex treatment in patients of Group 1, to whom PDRN was administered twice (on Days 1 and 6), the ulcer area decreased by $6.59 \%$ compared to Day 4 , which was statistically significant compared with Group 2.

On Days 12, 16 and 20, with continuing PDRN-therapy, the area of TUs decreased by $14.11 \%, 10.96 \%$ and $26.15 \%$, respectively, compared with the previous stage of observation. In Group 2, a decrease in the area of TUs was $4.35 \%, 2.27 \%$ and $3.49 \%$, respectively. Statistically significant differences between the two groups were observed on Days 8, 12, 16 and 20 (Table 2).

Data of Table 2 clearly show the rate of reduction in the skin defect area due to epithelialization of TUs in patients of both groups. Accelerated wound healing was observed in patients of Group 1 after Day 8 of treatment; in Group 2 without PDRN-therapy, similar acceleration was not observed.

In Group 1, after discharge from the hospital, TUs were completely healed by $32 \pm 1.2$ days (Figures 1 and 2 ). In Group 2 , we did not find complete epithelialization of TUs by this period of time.

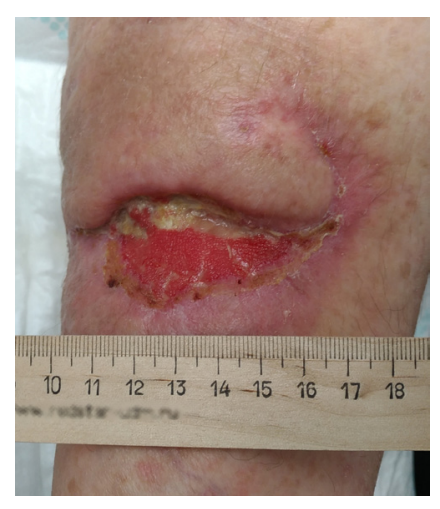

Fig. 1. Trophic ulcer before treatment.

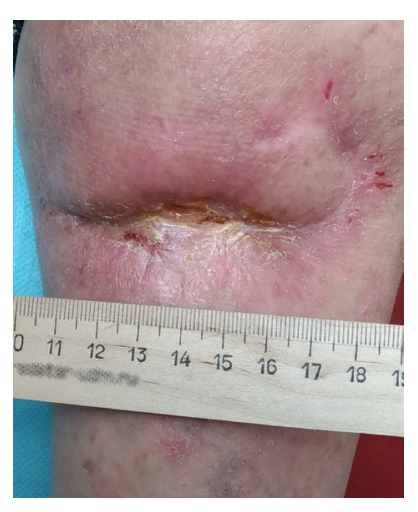

Fig. 2. Trophic ulcer on Day 20 of treatment
Since the temperature of the TU surface directly depends on the degree of microcirculation recovery, we used skin thermometry to indirectly characterize the changes in the blood supply to the plane of the ulcerative defect of the skin after PDRN injections. On Day 1 of treatment, the analysis of the temperature in the center of a $\mathrm{TU}$ and along its perimeter around the defect showed that this indicator had no statistically significant differences between the two groups $(P<0.05)$ (Table 3). In Group 1, by Day 20 a significant increase in the temperature of TU in the examined areas was found.

\section{Table 3.}

Dynamics of the TU surface temperature in the patients of study groups

\begin{tabular}{|l|c|c|c|c|}
\hline \multirow{2}{*}{ Temperature ${ }^{\circ} \mathrm{C}$} & \multicolumn{2}{|c|}{ Group 1 } & \multicolumn{2}{c|}{ Group 2 } \\
\cline { 2 - 5 } & Day 1 & Day 20 & Day 1 & Day 20 \\
\hline In the center of TU & $29.7 \pm 0.3^{\circ}$ & $32.3^{\circ} \pm 0.3^{\circ *}$ & $29.6 \pm 0.1^{\circ}$ & $31.4 \pm 0.3^{\circ}$ \\
\hline $\begin{array}{l}\text { Along the peri- } \\
\text { meter around } \\
\text { TU }\end{array}$ & $30.8 \pm 0.2^{\circ}$ & $32.9 \pm 0.3^{\circ *}$ & $30.7 \pm 0.1^{\circ}$ & $32.0 \pm 0.1^{\circ}$ \\
\hline
\end{tabular}

*- $P<0.05$ between Day 20 and Day 1 in Group 1 


\section{Discussion}

The skin wound-healing process includes 3 stages: an inflammation, a proliferation with the formation of granulation tissue, and remodeling or fibrosis. ${ }^{(15)}$ In long-term, non-healing ischemic wounds, elements of all three phases are simultaneously present, but inflammation predominates. ${ }^{(16)}$ Despite the fact that the exact mechanism of the influence of polynucleotides on the regeneration processes is not completely clear, it is known that they contribute to the enhancement of angiogenesis and collagen formation during the healing of nonhealing defects of the skin of various etiologies. ${ }^{(17)}$ PDRNs are expected to realize a significant regenerative effect, enhancing the metabolic processes in the dermis cells, increasing collagen and elastin production by fibroblasts, reducing the level of pro-inflammatory cytokine TNF-alpha and accelerating fibroblast differentiation into the proliferative phase of the wound process. ${ }^{(18)}$ Granulation tissue is formed earlier, more actively and moderately. Experimentally proven reduction of the inflammatory response and a decrease in the presence of inflammatory cells after PDRN-therapy accelerates scarring and re-epithelialization of the skin. ${ }^{(19)}$

As a result of our comparative study, we found that in patients of Group 1, who received PDRN-therapy in addition to standard treatment, by Day 20 there was a reduction in the TU area to $51.06 \pm 0.1 \%$ of the initial size; in patients of Group 2, who received only standard treatment, the TU area was $85.56 \pm 0.1 \%$ of the initial size. In Group 1, there also was a tendency toward accelerating epithelization, which was not observed in Group 2. We did not find in the available literature any information on the effect of PDRNs on the dynamics of epidermis regeneration in humans. According to our experimental data, the thickness of the epidermis was significantly greater in mice in all studied periods of skin wound healing after the introduction of polynucleotides than in the control group. ${ }^{(20)}$

Since wound regeneration is accompanied by fluctuations in the temperature of damaged tissues caused by exo- and endothermic biochemical mechanisms of the healing process, the study of the dynamics of the perifocal and local temperature makes it possible to assess the nature of the course of the wound process. Many authors use thermometry in the complex of a common objective marker of wound healing. $\left.{ }^{(21,22}\right)$ Thermometry of wounds in the clinic successfully uses various designs of noncontact infrared thermometers, which, compared to conventional mercury thermometers and electrothermometers, make it possible to measure the temperature with greater accuracy and discreteness, as well as being faster, more ergonomic and more comfortable for patients. ${ }^{(23)}$ Due to the absence of direct contact of the infrared thermometer with the tissues and body fluids of the patient, there is no need for special treatment and preparation for work. Also, this method of remote temperature measurement allows one to measure the temperature of an object without disturbing the heat balance of the process being studied. This study does not harm the patients, does not violate the physiological processes in their bodies and does not cause those inconveniences that arise during the direct contact of any thermometers with the object being examined.
According to our data, the temperature in the center of the ulcer and in its periphery increased in patients of Group 1 compared to patients of Group 2 by $2.79 \%$ and $2.74 \%$, respectively, indicating a better blood supply to the skin defect, possibly due to more active angiogenesis. Inadequate perfusion is an important factor in impaired wound healing. ${ }^{(10)}$ Previously conducted experimental studies, ${ }^{(17)}$ including those in our laboratory, ${ }^{(19)}$ showed that PDRNs accelerate wound healing and improve angiogenesis, possibly due to an increase in vascular endothelial growth factor (VEGF) synthesis and binding to adenosine A2 receptors in endotheliocytes, thereby improving blood supply and ulcer perfusion. ${ }^{(11,12)}$

\section{Conclusion}

Thus, the study of planimetric indices of TU healing on the background of CVI in patients of Group 1, for whom conventional therapeutic measures were supplemented by local application of PDRN-therapy, showed that the area of ulcers was statistically significantly reduced by Day 20 of treatment to $51.06 \pm 0.1 \%$ of the original size. At the same time, in Group 2, this indicator remained at the level of $85.56 \pm 0.1 \%$ of the initial size. The surface temperature in the center of the ulcer and in its periphery on Day 20 of a combination of standard therapy and PDRN- therapy increased by $2.79 \%$ and $2.74 \%$, respectively, compared to standard treatment. Temperature differences in the center and around the skin defect remained in both groups. The use of PDRN-therapy in the complex treatment of TUs on the background of CVI is clinically effective. The applied method contributed to accelerating the repair processes of the skin defect and improving vascularization, which reduced the healing time of trophic ulcers.

\section{Competing Interests} interests.

The authors declare that they have no competing

\section{References}

1. Tolstoy PI, Tamrazova OB, Pavlenko VV, Kuleshov IYu, Tolstoy MP. Prolonged non-healing wounds and ulcers (pathogenesis, clinic, treatment). M.: Deepak; 2009. [In Russian]. 2. Obolensky VN, Rodoman GV, Nikitin VG, Karev MA. Trophic ulcers of the lower extremities - a review of the problem. Russian Medical Journal. 2009;(25):1647-63. [Article in Russian].

3. Brem H, Tomic-Canic M, Tarnovskaya A, Ehrlich HP, Baskin-Bey E, Gill K, et al. Healing of elderly patients with diabetic foot ulcers, venous stasis ulcers, and pressure ulcers. Surg Technol Int. 2003;11:161-7.

4. Budgen V. Evaluating the impact on patients of living with a leg ulcer. Nurs Times. 2004;100(7):30-1.

5. Saltmarche AE. Low level laser therapy for healing acute and chronic wounds- the extendicare experience. Int Wound J. 2008;5(2):351-60. doi: 10.1111/j.1742-481X.2008.00491.x. 6. Menke NB, Ward KR, Witten TM, Bonchev DG, Diegelmann RF. Impaired wound healing. Clin Dermatol. 2007;25(1):19-25. 
7. Mikhailov AYu, Pronichev VV, Solov'ev AA, Styazhkina SN, Chernenkova LM, Ledneva AL. The effectiveness of stimulating auto-factors for the regeneration of local inflammatory and ulcerative processes. Perm Medical Journal. 2014;33(5):58-64. [Article in Russian].

8. Fraccalvieri M, Salomone M, Di Santo C, Ruka E, Morozzo U, Bruschi S. Quantum molecular resonance technology in hard-to-heal extremity wounds: histological and clinical results. Int Wound J. 2017;14(6):1313-1322. doi: 10.1111/iwj.12805.

9. Pang C, Ibrahim A, Bulstrode NW, Ferretti P. An overview of the therapeutic potential of regenerative medicine in cutaneous wound healing. Int Wound J. 2017;14(3):450-459. doi: 10.1111/iwj.12735

10. Shin J, Park G, Lee J, Bae H. The effect of polydeoxyribonucleotide on chronic non-healing wound of an amputee: a case report. Ann Rehabil Med. 2018;42(4):630633. doi.org/10.5535/arm.2018.42.4.630.

11. Lee JH, Han JW, Byun JH, Lee WM, Kim MH, Wu WH. Comparison of wound healing effects between Oncorhynchus keta-derived polydeoxyribonucleotide (PDRN) and Oncorhynchus mykiss-derived PDRN. Arch Craniofac Surg. 2018;19(1):20-34. doi: 10.7181/acfs.2018.19.1.20.

12. Kim JY, Pak CS, Park JH, Jeong JH, Heo CY. Effects of polydeoxyribonucleotide in the treatment of pressure ulcers. J Korean Med Sci. 2014;29 Suppl 3:S222-7. doi: 10.3346/ jkms.2014.29.S3.S222.

13. Noh TK, Chung BY, Kim SY, Lee MH, Kim MJ, Youn CS, Lee MW, et al. Novel anti-melanogenesis properties of polydeoxyribonucleotide, a popular wound healing booster. Int J Mol Sci. 2016;17(9):E1448. doi: 10.3390/ijms17091448. 14. Hwang KH, Kim JH, Park EY, Cha SK. An effective range of polydeoxyribonucleotides is critical for wound healing quality. Mol Med Rep. 2018;18(6):5166-72. doi: 10.3892/mmr.2018.9539. 15. Danilov RK. Wound process: Histogenetic basis. SPb.:VMedA; 2008. [In Russian].

16. Fedorov DN, Ivashkin AN, Shinin VV, Vasil'ev AV,
Ivanov AA. [Morphological and immunohistochemical characteristics of repar processes in nonhealing wounds]. Arh Patol. 2002;64(1): 8-11. [Article in Russian].

17. Bitto A, Polito F, Altavilla D, Minutoli L, Migliorato A, Squadrito F. Polydeoxyribonucleotide (PDRN) restores blood flow in an experimental model of peripheral artery occlusive disease. J Vasc Surg. 2008;48(5):1292-300. doi: 10.1016/j. jvs.2008.06.041.

18. Bitto A, Oteri G, Pisano M, Polito F, Irrera N, Minutoli L, Squadrito F, Altavilla D. Adenosine receptor stimulation by polynucleotides (PDRN) reduces inflammation in experimental periodontitis. J Clin Periodontol. 2013;40(1):2632. doi: $10.1111 /$ jcpe. 12010 .

19. Shapovalova YeYu, Boyko TA, Baranovskiy YuG, Harchenko SV, Yunsi GA. [Influence of polynucleotides on the content of macrophages in regenerating ischemic wound]. Modern Problems of Science and Education. 2017;6. URL: http://www.scienceeducation.ru/ru/article/view?id=27352 [Article in Russian].

20. ShapovalovaYeYu,BoykoTA,BaranovskiyYuG,Kolomoyetz TA, Vasilenko SA. [The morphological peculiarities of the skin tissue are under the skin of the polydeoxyribonucleotide]. Crimea Journal of Experimental and Clinical Medicine. 2017;7(4):85-90. [Article in Russian].

21. Mufti A, Somayaji R, Coutts P, Sibbald RG. Infrared Skin Thermometry: Validating and Comparing Techniques to Detect Periwound Skin Infection. Adv Skin Wound Care. 2018;31(1):607611. doi: 10.1097/01.ASW.0000527352.75716.70.

22. Sibbald RG, Mufti A, Armstrong DG. Infrared skin thermometry: an underutilized cost-effective tool for routine wound care practice and patient high-risk diabetic foot selfmonitoring. Adv Skin Wound Care. 2015;28(1):37-44; quiz 45-6. doi: 10.1097/01.ASW.0000458991.58947.6b.

23. Langemo DK, Spahn JG. A Reliability Study Using a LongWave Infrared Thermography Device to Identify Relative Tissue Temperature Variations of the Body Surface and Underlying Tissue. Adv Skin Wound Care. 2017;30(3):109119. doi: 10.1097/01.ASW.0000511535.31486.bb. 